\title{
The Effects of Sodium Carbonate and Bicarbonate Treatments on Sisal Fibre Composites
}

\author{
Júlio Cesar dos Santos ${ }^{a}{ }^{(1)}$, Pablo Resende Oliveira ${ }^{b}$, Rodrigo Teixeira Santos Freire ${ }^{a}$ (D), \\ Luciano Machado Gomes Vieirac, Juan Carlos Campos Rubio ${ }^{c}$ (D), Túlio Hallak Panzera * (D) \\ ${ }^{a}$ Universidade Federal de São João del-Rei, Centro de Inovação e Tecnologia em Compósitos (CITeC), \\ Praça Frei Orlando, 170, 36307-352, São João del-Rei, MG, Brasil. \\ ${ }^{b}$ Albert-Ludwigs-Universität Freiburg, Department of Sustainable Systems Engineering (INATECH), \\ Freiburg im Breisgau, Germany. \\ ${ }^{c}$ Universidade Federal de Minas Gerais, Escola de Engenharia, Belo Horizonte, MG, Brasil.
}

Received: September 14, 2021; Revised: November 19, 2021; Accepted: December 14, 2021

This work investigates the effect of eco-friendly chemical treatments on the mechanical and physical properties of composite laminates based on sisal fibres. A $2^{2} 3^{1}$ full-factorial design is conducted to test the influence of chemical solution types, fibre treatment time, and polymer matrix type on the mechanical and morphological characterisation of the composites. Chemical treatments remove impurities from fibre surfaces, and enhance fibre-matrix adhesion. The treatments, especially with sodium carbonate $\left(\mathrm{Na}_{2} \mathrm{CO}_{3}\right)$, also progressively reduce the hemicellulose fibre content. Polyester composites made with sisal fibres treated with $\mathrm{Na}_{2} \mathrm{CO}_{3}$ for $96 \mathrm{~h}$ achieve enhanced strength and stiffness under tensile, compressive and impact loads. The results evidence the feasibility and efficiency of the proposed eco-friendly treatments for natural fibres and the application of renewable fibre laminates in secondary structural applications.

Keywords: Epoxy, polyester, sisal, sodium carbonate, sodium bicarbonate.

\section{Introduction}

The need for materials with high mechanical performance with reduced environmental impact has driven several types of research on composites based on bio-sourced components. In addition to their mechanical performance, laminates made with natural fibres, such as flax, jute, sisal, coir and kenaf, are attractive due to their reduced cost, low density, and biodegradability and renewability ${ }^{1,2}$. However, one of the significant drawbacks of natural fibres is their reduced adhesion to the polymer matrix. Natural fibres are hydrophilic, while polymeric matrices are generally hydrophobic ${ }^{3,4}$. Despite their limitations, the application of these materials has risen in different sectors, such as the construction and automotive industries. The choice of the polymeric matrix is also an essential aspect of natural fibres laminates performance. The type of polymer is determined according to the degradation temperature of the natural fibres, generally limited to $200^{\circ} \mathrm{C}$. Although thermoplastic polymers present improved recyclability, thermosetting polymers possess superior mechanical properties, and some of them can be cured at relatively low temperatures, such as epoxy and polyester ${ }^{5}$.

Sisal is one of the most abundant natural fibres, used in ropes, carpets, handicrafts, textiles and papers. Extracted from leaves of the sisal plant (Agave sisalana), the annual production of sisal fibres reached about 4.5 million tonnes, mainly in tropical countries, such as Tanzania and Brazil ${ }^{6,7}$.

*e-mail: panzera@ufsj.edu.br
The abundance and high strength of sisal fibres motivated their use as composite reinforcement in several studies ${ }^{8}$.

Several chemical treatments have been applied to enhance fibre-matrix adhesion, such as mercerisation/alkalinisation, grafting, acrylation, acetylation and silanisation. The alkali treatment has been the most used, even though traditional alkali treatments are incredibly harmful to the environment. Eco-friendly mercerisation has been studied in recent years to reduce the environmental impact of treatment chemicals disposal. Fiore et al. ${ }^{9-11}$ and Chaitanya and Singh ${ }^{12}$ initially proposed sustainable fibre treatments based on sodium bicarbonate $\left(\mathrm{NaHCO}_{3}\right)$. Fiore et al. ${ }^{9}$ applied a statistical approach and the Weibull distribution to analyse the tensile performance of sisal fibres. The treatment with sodium bicarbonate for $24,120,240$ hours increased the fibre elastic modulus by $63.23 \%, 115.01 \%$ and $138.44 \%$, respectively. In contrast, sisal-fibre-reinforced PLA composites achieved an increase in tensile and flexural moduli of $48.8 \%$ and $39.3 \%$, respectively, considering 72 hours of treatment with sodium bicarbonate $^{12}$.

Furthermore, Santos et al. studied the effect of sodium carbonate $\left(\mathrm{Na}_{2} \mathrm{CO}_{3}\right)^{13}$ and sodium bicarbonate on the properties of coir fibres ${ }^{14}$. Both carbonates act as mild alkali in aqueous solutions and can be handled safely. Both alkali solutions release sodium $(\mathrm{Na}+)$ and hydroxide $\left(\mathrm{OH}^{-}\right)$ ions. The $\mathrm{OH}$ groups present in fibres correspond mainly to alcoholic hydroxyls (weak acids). The breakdown of $\mathrm{NaHCO}_{3}$ and $\mathrm{Na}_{2} \mathrm{CO}_{3}$ into hydroxide ions and carbonic acid in the presence of water renders a mild and strong 
alkaline nature for the aqueous solution, respectively ${ }^{9,12-15}$. Therefore, it is expected that aqueous solutions of $\mathrm{NaHCO}_{3}$ and $\mathrm{Na}_{2} \mathrm{CO}_{3}$ behave similarly to the $\mathrm{NaOH}$ solution while reacting with lignocellulose fibres, as shown for sisal ${ }^{9,12}$, kenaf $^{10}$, flax ${ }^{11}$ and coir $^{13-14}$ fibres. However, both alkaline solutions generally take longer than highly alkaline sodium hydroxide solutions ${ }^{12}$, usually between 24 and 120 hours, to achieve the desired results.

This work investigates the effects of sodium bicarbonate and sodium carbonate eco-friendly treatments of sisal fibres on the mechanical properties of composite materials. Thermosetting polymers (epoxy and polyester) are used as a matrix phase to prevent damage to the natural fibres caused by thermoplastic fabrication, such as high temperature and compaction levels. Post-treatment morphological analyses are conducted on the fibres, and quantitative results are assessed statistically using the Design of Experiment (DoE) and ANOVA techniques.

\section{Materials and Methods}

\subsection{Materials}

Commercially available sisal fibre mats are supplied by Sisal Sul (São Paulo - Brazil). The matrix is based on two polymers: epoxy resin (Renlan M and hardener HY 956) and polyester resin with MEK (methyl-ethyl acetone) catalyst supplied by Huntsman (Brazil) and Reichhold (Brazil), respectively. Powdered sodium bicarbonate $\left(\mathrm{NaHCO}_{3}\right)$ and carbonate $\left(\mathrm{Na}_{2} \mathrm{CO}_{3}\right)$ are sourced by Synth (Brazil) and Solvay (Brazil), respectively.

\subsection{Design of experiments}

A full-factorial design of experiments $\left(2^{2} 3^{1}\right)$ is carried out to identify the effects of treatment type $\left(\mathrm{NaHCO}_{3}\right.$ and $\left.\mathrm{Na}_{2} \mathrm{CO}_{3}\right)$, treatment time $(24 \mathrm{~h}, 96 \mathrm{~h}, 168 \mathrm{~h})$, and polymer type (epoxy and polyester) on the mechanical properties of sisal fibre laminates. The twelve experimental conditions are summarised in Table 1. The effect of each factor on the response is evidenced by the $p$-value obtained using the Minitab v.18 statistical software. A $p$-value less than or equal to 0.05 indicates that an individual factor or interaction is statistically significant considering a $95 \%$ confidence interval. An interaction indicates that the effect of a particular factor depends on the level of another factor. Two reference conditions based on untreated sisal fibre reinforced epoxy (REF 1) and polyester (REF 2) are also tested and compared to other conditions using Tukey's mean comparison test.

The predictability of the statistical model is determined by the value of $\mathrm{R}^{2}$ (adj). A model with greater predictability is indicated with an $\mathrm{R}^{2}$ (adj) close to $100 \%$. The DoE findings are valid only for data that follow the normal distribution. The normality of the residuals is verified with the Anderson-Darling test. A $p_{A D}$-value greater than 0.05 indicates that the data followed a normal distribution, validating the DoE results ${ }^{16}$.

\subsection{Manufacturing and testing}

The sisal fibres are treated to remove dirt and ensure better bonding to the polymer. The aqueous solutions of $10 \%(\mathrm{w} / \mathrm{v})$ $\mathrm{Na}_{2} \mathrm{CO}_{3}$ and $\mathrm{NaHCO}_{3}{ }^{12-14}$ are stirred for 5 and 30 minutes, respectively, until total homogenisation. Table 2 presents the main characteristics of treatment solutions. The sisal fibres (as received) are soaked in the aqueous solutions at room temperature $\left(\sim 23^{\circ} \mathrm{C}\right)$. The fibres are removed at different time intervals $(24,96$ and $168 \mathrm{~h})$ and subsequently washed in running water at room temperature ${ }^{13,14}$. The treated sisal fibres are oven-dried at $60{ }^{\circ} \mathrm{C}$ for 5 hours. The dry fibres are stored in plastics bags until the composite is manufactured.

After treatment, sisal fibre-reinforced epoxy (SFRE) and polyester (SFRP) composites are manufactured with a fibre volume fraction of $30 \%$. This fibre volume fraction was set based on several preliminary tests to achieve a smooth surface without macropores. The grammage of sisal fibre is determined

Table 1. Experimental conditions, full-factorial design $\left(2^{2} 3^{1}\right)$.

\begin{tabular}{cccc}
\hline Conditions & Matrix Type & Treatment Type & Treatment Time (h) \\
\hline $\mathrm{C} 1$ & Epoxy & $\mathrm{NaHCO}_{3}$ & 24 \\
\hline $\mathrm{C} 2$ & Epoxy & $\mathrm{NaHCO}_{3}$ & 96 \\
\hline $\mathrm{C} 3$ & Epoxy & $\mathrm{NaHCO}_{3}$ & 168 \\
\hline $\mathrm{C} 4$ & Epoxy & $\mathrm{Na}_{2} \mathrm{CO}_{3}$ & 24 \\
\hline $\mathrm{C} 5$ & Epoxy & $\mathrm{Na}_{2} \mathrm{CO}_{3}$ & 96 \\
\hline $\mathrm{C} 6$ & $\mathrm{Na}_{2} \mathrm{CO}_{3}$ & 168 \\
\hline $\mathrm{C} 7$ & $\mathrm{NaHCO}_{3}$ & 24 \\
\hline $\mathrm{C} 8$ & Epoxy & $\mathrm{NaHCO}_{3}$ & 96 \\
\hline $\mathrm{C} 9$ & $\mathrm{NaHCO}_{3}$ & 168 \\
\hline $\mathrm{C} 10$ & Polyester & $\mathrm{Na}_{2} \mathrm{CO}_{3}$ & 24 \\
\hline $\mathrm{C} 11$ & Polyester & $\mathrm{Na}_{2} \mathrm{CO}_{3}$ & 96 \\
\hline $\mathrm{C} 12$ & Polyester & $\mathrm{Na}_{2} \mathrm{CO}_{3}$ & 168 \\
\hline
\end{tabular}

Table 2. $\mathrm{Na}_{2} \mathrm{CO}_{3}$ and $\mathrm{NaHCO}_{3}$ solutions characteristics.

\begin{tabular}{cccc}
\hline Solution & $\mathrm{pH}$ & {$[\mathrm{OH}-]$} & Counterion \\
\hline $\mathrm{Na}_{2} \mathrm{CO}_{3}$ & 11.80 & $6.42 \times 10^{-3}$ & {$\left[\mathrm{Na}^{+}\right]=1.868$} \\
\hline $\mathrm{NaHCO}_{3}$ & 8.30 & $2.04 \times 10^{-3}$ & {$\left[\mathrm{Na}^{-3}\right]=1.190$} \\
\hline
\end{tabular}


as $900 \mathrm{~g} / \mathrm{cm}^{217}$. A hybrid manufacturing process consisting of hand lay-up and uniaxial cold pressing is considered. This method is based on the procedures adopted by Santos and Oliveira et al. ${ }^{13,17-18}$. Two sheets of waxed aluminium are used for the compaction process. An aluminium sheet is placed into a metal mould $\left(310 \times 310 \times 4 \mathrm{~mm}^{3}\right)$, being covered with a thin film of resin $(40 \%$ of the total matrix mass) (Figure 1a). Such an initial polymer layer is applied to the mould surface to ensure surface wettability of the fibres and a proper composite surface finish, free of voids or imperfections. Then, the sisal fibre mat and the remaining polymer system are added to the mould (Figure 1b). The second aluminium sheet is laid over the fibres, and the metal mould is closed under a uniaxial pressure of $645 \mathrm{kPa}$ (Figure 1c). The lid is fixed by steel bars to ensure sample thickness and applied pressure. The $310 \times 310 \times 2.5 \mathrm{~mm}^{3}$ sandwich panels are removed after 15 hours and subsequently post-cured for 14 days in sealed bags to protect against moisture (Figure 1d).

After curing, the laminates are cut to specific sizes using a band saw (Makita LB1200F) to standard test dimensions. No coolant is used in cutting. Due to the low thickness of the laminates and random fibre orientation, no heat degradation or delamination is observed after cutting. Tensile, flexural, and compression tests are conducted on a Shimadzu AGX-Plus Universal Machine with a $100 \mathrm{kN}$ load cell. Six (6) $250 \times$ $25 \times 2.5 \mathrm{~mm}^{3}$ tensile samples are tested for each condition using a video-extensometer for strain measurement following ASTM D3039 ${ }^{19}$. The flexural tests are performed according to ASTM D79020, with samples $13 \mathrm{~mm}$ wide and 32 times longer than the specimen thickness. Twenty (20) bending samples are tested for each experimental condition. The compressive test is performed using $90 \times 15 \times 2.5 \mathrm{~mm}^{3}$ samples following the ASTM D6641/D6641M standard ${ }^{21}$. Based on ASTM standard protocols ${ }^{19-21}$ and other works reported in the literature ${ }^{12-13,17-18}$, tensile, bending and compression tests are conducted at $2 \mathrm{~mm} / \mathrm{min}$. The impact test is performed on twenty (20) samples for each condition. $80 \times 10 \times 2.5 \mathrm{~mm}^{3}$ samples are tested following ISO 179-1 guideline ${ }^{22}$ at $15 \mathrm{~J}$ impact energy on a Charpy Impact Tester (XJJ Series). Tests are conducted at controlled temperature $\left(\sim 23^{\circ} \mathrm{C}\right)$ and humidity (55-58\%). The fracture mode of sisal-based composites is analysed with a Hitachi TM 3000 microscope.

The effect of chemical treatments on the surface of sisal fibres is observed in backscattered electron images obtained by scanning electron microscopy (Philips XL-30 FEG). FTIR Spectroscopy and X-ray diffraction are used to assess the removal of surface compounds and crystalline structures. Untreated and treated sisal fibre bundles are aligned and lacerated into micro-segments for FTIR and X-ray diffraction measurements. FTIR spectra are acquired using a Shimadzu IR Prestige-21 spectrometer with an attenuated total reflection (ATR) probe. Each sample is scanned from 4000 to $400 \mathrm{~cm}^{-1}$ wavelength with a $4 \mathrm{~cm}^{-1}$ resolution. X-ray diffraction is analysed using a Rigaku Ultima IV X-ray diffractometer operating with $\mathrm{CuK} \alpha$ radiation $(\lambda=0.15418 \mathrm{~nm})$. Diffraction patterns are obtained for $2 \theta$ values ranging from 5 to $40^{\circ}$ in continuous scan mode at $1 \% \mathrm{~min}$. The crystallinity index (Ic) of the samples is calculated using Equation 1. $\mathrm{I}_{002}$ is the maximum diffraction intensity in the crystallographic

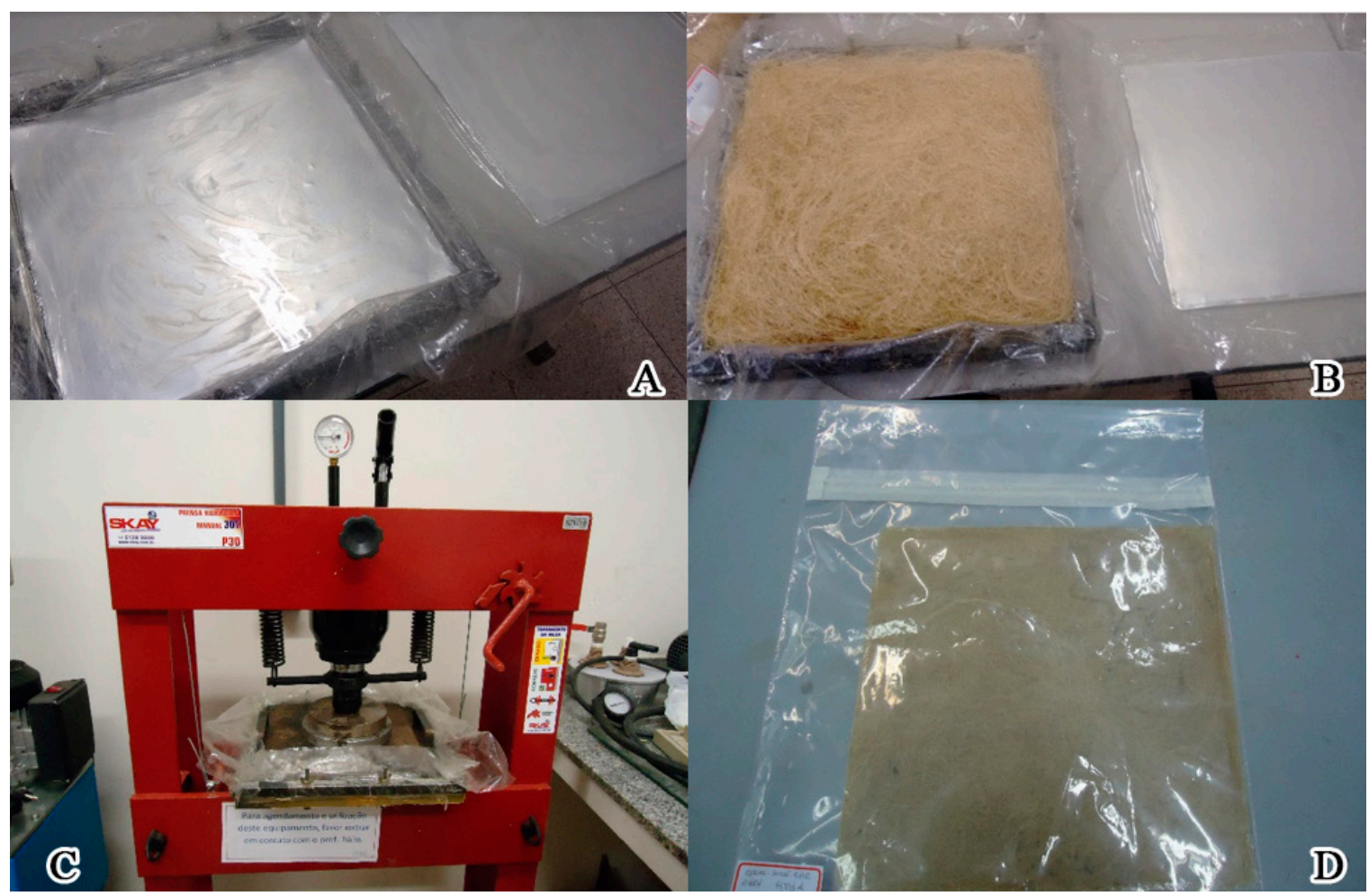

Figure 1. Manufacturing process steps: a) mould with aluminium surfaces covered by resin; b) sisal embedded with epoxy inside the mould; c) compaction pressure; d) composites sealed with bags (post-curing process). 
plane (002) at an angle $2 \theta$ between $22^{\circ}$ and $23^{\circ} . \mathrm{I}_{\mathrm{am}}$ is the diffraction intensity of the amorphous material taken at a $2 \theta$ angle between $18^{\circ}$ and $19^{\circ}$, where the intensity is minimal.

$I_{C}=\frac{I_{002}-I_{a m}}{I_{002}} \times 100$

The thermal degradation of raw and treated sisal fibres is evaluated with varying treatment times, using a Shimadzu DTG-60H differential thermal analyser. Analyses are carried out under a nitrogen atmosphere at a constant flow $(\sim 100$ $\mathrm{mL} / \mathrm{min}$ ), a heating rate of $10^{\circ} \mathrm{C} / \mathrm{min}$ and a temperature range of 30 to $800^{\circ} \mathrm{C}$.

\section{Results}

The mechanical results of sisal fibre-based laminates are shown in Table 3. Mean values and standard deviations for tensile modulus $\left(\mathrm{E}_{\mathrm{T}}\right)$ and strength $\left(\sigma_{\mathrm{T}}\right)$, flexural modulus $\left(\mathrm{E}_{\mathrm{F}}\right)$ and strength $\left(\sigma_{\mathrm{F}}\right)$, impact resistance $\left(\mathrm{S}_{\mathrm{I}}\right)$ and compressive strength $\left(\sigma_{\mathrm{C}}\right)$ are reported for each DoE condition in Table 3. Additionally, reference conditions (laminates with untreated fibres) and responses for pristine epoxy and polyester polymer are included in Table 3. Fibre inclusion increases the stiffness and impact resistance of sisal fibre composites compared to pure polymers. In contrast, composite strength exhibits a non-regular trend compared to matrix strength. The DoE responses obtained in mechanical tests are statistically analysed using the Analysis of Variance (ANOVA) technique. The ANOVA results are shown in Table 4. P-values less than 0.05 indicate that most responses are affected by a thirdorder interaction of the factors, except tensile strength and stiffness. The results of $\mathrm{R}^{2}$ (adj) range from 91.33 to $97.09 \%$, indicating excellent predictability of the subjacent statistical model used. Anderson-Darling tests also indicate $p_{A D}$-values greater than 0.05 for all responses, ensuring the validity of the ANOVA $^{16}$. P-values in italics (Table 4) correspond to factors or interactions analysed using effect plots. When higherorder effects are significant, only interactions are analysed.

\subsection{Tensile properties}

Tensile modulus is affected only by the main factors, as shown in Table 4. The main-effect plots for the tensile modulus of sisal fibre composites are shown in Figure 2. Reference lines for untreated sisal fibre polyester (USFPC) and epoxy

Table 3. Mechanical properties of polymers and sisal based -epoxy and -polyester composites. The standard deviation is presented in parentheses.

\begin{tabular}{|c|c|c|c|c|c|c|c|}
\hline \multirow{2}{*}{ Matrix phase } & \multirow{2}{*}{ Fibre Reinforcement } & $\mathrm{E}_{\mathrm{T}}$ & $\sigma_{\mathrm{T}}$ & $\mathrm{E}_{\mathrm{F}}$ & $\sigma_{\mathrm{F}}$ & $\mathrm{S}_{\mathrm{I}}$ & $\sigma_{\mathrm{C}}$ \\
\hline & & {$[\mathrm{GPa}]$} & {$[\mathrm{MPa}]$} & {$[\mathrm{GPa}]$} & {$[\mathrm{MPa}]$} & {$\left[\mathrm{kJ} / \mathrm{m}^{2}\right]$} & {$[\mathrm{MPa}]$} \\
\hline \multirow[t]{7}{*}{ Epoxy } & Untreated & $3.70(0.02)$ & $26.00(0.86)$ & $2.89(0.14)$ & $53.77(1.47)$ & $21.33(0.15)$ & $69.55(6.20)$ \\
\hline & $\mathrm{NaHCO}_{3}-24 \mathrm{~h}$ & $4.70(0.01)$ & $34.04(0.64)$ & $3.13(0.16)$ & $58.41(2.57)$ & $20.82(0.18)$ & $63.74(1.82)$ \\
\hline & $\mathrm{NaHCO}_{3}-96 \mathrm{~h}$ & $5.23(0.34)$ & $36.94(0.46)$ & $3.44(0.04)$ & $63.55(0.62)$ & $27.58(0.69)$ & $62.09(2.96)$ \\
\hline & $\mathrm{NaHCO}_{3}-168 \mathrm{~h}$ & $3.86(0.10)$ & $31.80(0.82)$ & $2.88(0.05)$ & $55.71(0.54)$ & $22.06(0.08)$ & $48.82(1.08)$ \\
\hline & $\mathrm{Na}_{2} \mathrm{CO}_{3}-24 \mathrm{~h}$ & $5.12(0.08)$ & $37.73(0.90)$ & $3.44(0.03)$ & $60.72(1.17)$ & $18.93(0.62)$ & $69.00(1.05)$ \\
\hline & $\mathrm{Na}_{2} \mathrm{CO}_{3}-96 \mathrm{~h}$ & $5.76(0.46)$ & $38.74(1.60)$ & $3.80(0.07)$ & $65.76(1.06)$ & $19.69(0.84)$ & $73.45(3.01)$ \\
\hline & $\mathrm{Na}_{2} \mathrm{CO}_{3}-168$ & $4.50(0.14)$ & $30.61(0.83)$ & $3.04(0.05)$ & $59.52(1.27)$ & $18.47(0.17)$ & $64.03(0.40)$ \\
\hline \multirow[t]{7}{*}{ Polyester } & Untreated & $4.52(0.19)$ & $31.22(3.17)$ & $3.11(0.05)$ & $45.00(1.94)$ & $20.51(0.36)$ & $76.35(3.35)$ \\
\hline & $\mathrm{NaHCO}_{3}-24 \mathrm{~h}$ & $5.64(0.15)$ & $26.72(0.86)$ & $3.19(0.12)$ & $50.38(1.83)$ & $23.05(0.97)$ & $66.84(0.98)$ \\
\hline & $\mathrm{NaHCO}_{3}-96 \mathrm{~h}$ & $5.68(0.29)$ & $30.78(0.92)$ & $3.82(0.16)$ & $59.38(0.99)$ & $28.94(0.16)$ & $78.83(0.84)$ \\
\hline & $\mathrm{NaHCO}_{3}-168 \mathrm{~h}$ & $5.17(0.25)$ & $29.52(1.95)$ & $3.67(0.15)$ & $57.11(1.48)$ & $22.91(0.53)$ & $66.03(5.24)$ \\
\hline & $\mathrm{Na}_{2} \mathrm{CO}_{3}-24 \mathrm{~h}$ & $6.23(0.09)$ & $34.83(0.59)$ & $3.96(0.02)$ & $67.59(0.39)$ & $22.76(0.91)$ & $80.71(0.10)$ \\
\hline & $\mathrm{Na}_{2} \mathrm{CO}_{3}-96 \mathrm{~h}$ & $6.50(0.14)$ & $39.81(0.36)$ & $3.97(0.05)$ & $69.39(2.18)$ & $26.41(0.23)$ & $83.79(0.20)$ \\
\hline & $\mathrm{Na}_{2} \mathrm{CO}_{3}-168$ & $5.39(0.08)$ & $36.15(0.40)$ & $3.78(0.08)$ & $57.34(2.19)$ & $23.48(0.08)$ & $79.80(0.46)$ \\
\hline \multicolumn{2}{|c|}{ Neat epoxy polymer } & $2.24(0.11)$ & $47.29(2.00)$ & $2.14(0.04)$ & $69.28(3.9)$ & $8.74(1.4)$ & $65.76(1.88)$ \\
\hline \multicolumn{2}{|c|}{ Neat polyester polymer } & $2.44(0.14)$ & $39.82(3.00)$ & $2.19(0.08)$ & $55.83(2.90)$ & $5.81(0.31)$ & $83.53(3.02)$ \\
\hline
\end{tabular}

Table 4. ANOVA (DoE) results for mechanical tests.

\begin{tabular}{|c|c|c|c|c|c|c|c|}
\hline \multicolumn{2}{|c|}{ Factors and interactions } & $\begin{array}{c}\text { Tensile } \\
\text { modulus }\end{array}$ & $\begin{array}{r}\text { Tensile } \\
\text { strength }\end{array}$ & $\begin{array}{l}\text { Flexural } \\
\text { modulus }\end{array}$ & $\begin{array}{l}\text { Flexural } \\
\text { strength }\end{array}$ & $\begin{array}{l}\text { Impact } \\
\text { strength }\end{array}$ & $\begin{array}{c}\text { Compressive } \\
\text { strength }\end{array}$ \\
\hline \multirow[t]{7}{*}{ P-Value } & Matrix type (MT) & 0.000 & 0.000 & 0.000 & 0.000 & 0.538 & 0.000 \\
\hline & Treatment type (TTy) & 0.000 & 0.000 & 0.000 & 0.000 & 0.000 & 0.000 \\
\hline & Treatment Time (TTi) & 0.000 & 0.000 & 0.000 & 0.000 & 0.000 & 0.000 \\
\hline & MT*TTy & 0.946 & 0.000 & 0.391 & 0.000 & 0.001 & 0.884 \\
\hline & $\mathrm{MT}^{*} \mathrm{TT} \mathrm{i}$ & 0.082 & 0.000 & 0.000 & 0.132 & 0.266 & 0.003 \\
\hline & TTy*TTi & 0.519 & 0.014 & 0.004 & 0.000 & 0.000 & 0.026 \\
\hline & MT*TTy*TTi & 0.241 & 0.216 & 0.011 & 0.016 & 0.001 & 0.012 \\
\hline \multicolumn{2}{|c|}{$\mathrm{R}^{2}$ (adj) } & $91.33 \%$ & $94.26 \%$ & $93.47 \%$ & $94.00 \%$ & $97.09 \%$ & $95.50 \%$ \\
\hline \multicolumn{2}{|c|}{ A.D. (P-Value $\geq 0.05$ ) } & 0.931 & 0.151 & 0.628 & 0.124 & 0.583 & 0.287 \\
\hline
\end{tabular}


(USFEC) composites are added to this plot, revealing that both treatments are able to enhance the material stiffness. The polyester-based composites consisting of fibres treated with $\mathrm{Na}_{2} \mathrm{CO}_{3}$ for 96 hours have the highest modulus. Polyesterbased composites exhibit $18.72 \%$ higher tensile modulus than epoxy-based composites (Figure 2, plot i), while conventional sodium bicarbonate treatment reduces its stiffness by $9.68 \%$ (Figure 2, plot ii) compared to the sodium carbonate treatment. The longer treatment time increases stiffness by $6.83 \%$ for up to 96 hours, presenting a significant drop of $18.31 \%$ for 168 hours (Figure 2, plot iii). Enhanced results for treatments up to 96 hours agree with previous findings, which indicated that treatments longer than 96 hours induce microstructural fibre damage and losses in lignin chains ${ }^{13}$. The tensile modulus improvement was also obtained by
Chaitanya and Singh ${ }^{12}$ using sodium bicarbonate solution treatment. The alkaline treatment modifies the fibre surface due to the removal of external compounds, such as cellulose and hemicellulose, which causes a greater exposure of lignin (a natural phenolic polymer ${ }^{23}$ ), and, consequently, makes it more compatible with polyester-based composites ${ }^{13,24}$. The increased stiffness of polyester composites can be attributed to a better transfer of stresses between the polyester matrix and the stiff sisal fibres ${ }^{12}$.

Tensile strength is affected by the main and second-order interaction effects, as shown in Table 4. Figure 3 (plot i) shows that epoxy-based composites consisting of fibres treated with $\mathrm{NaHCO}_{3}$ provide $18.14 \%$ higher strength than polyester composites. In contrast, the alternative treatment with sodium carbonate $\left(\mathrm{Na}_{2} \mathrm{CO}_{3}\right)$ increases the strength of

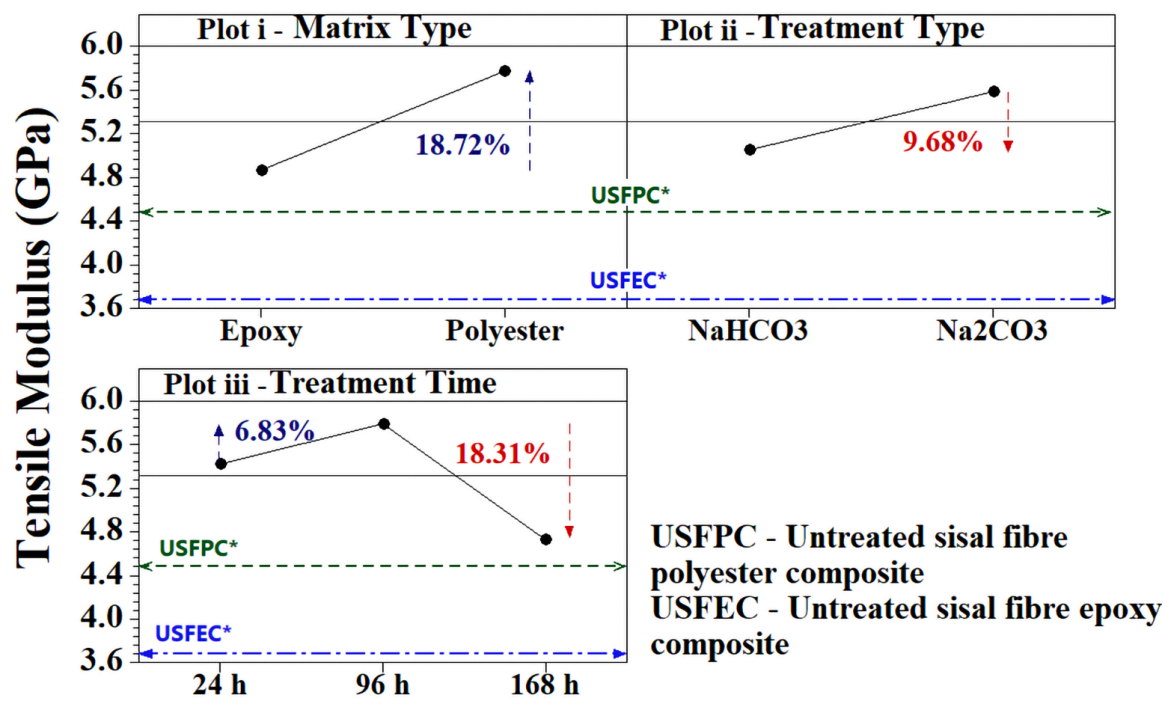

Figure 2. Main effect plots for the mean tensile modulus.

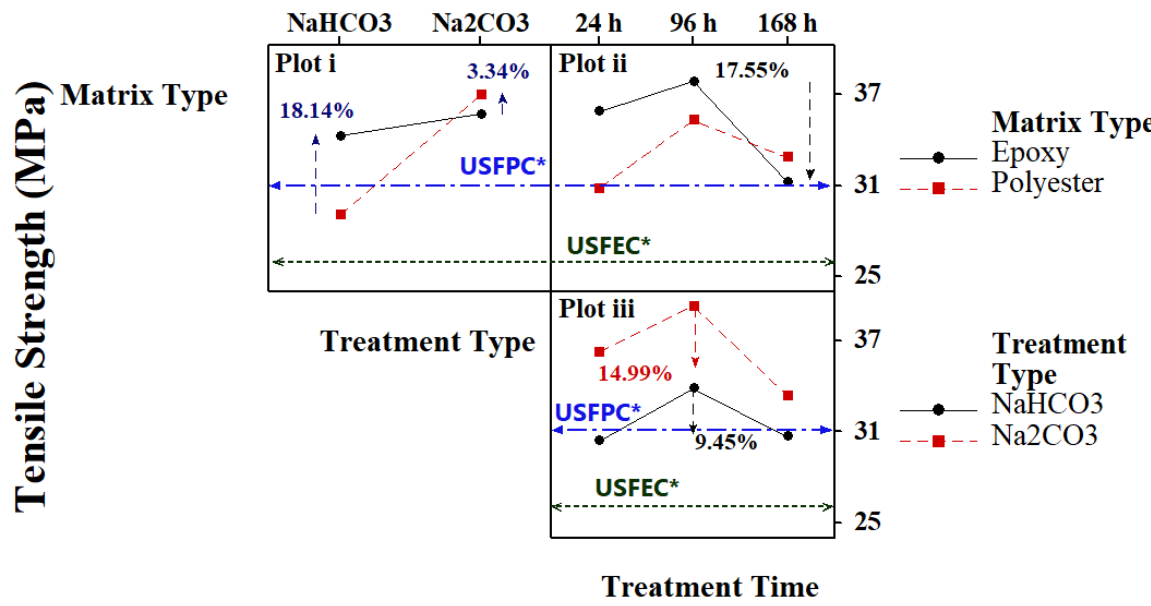

\section{USFPC - Untreated sisal fibre polyester composite USFEC - Untreated sisal fibre epoxy composite}

Figure 3. Tensile testing plots for DoE: tensile strength interaction plots for i) Matrix type $x$ Treatment Type; ii) Matrix type $x$ Treatment time, and iii) Treatment Time x Treatment Type. 
polyester-based laminates, as shown in Figure 3 (plot i). The 96-hour exposure time provides improved strength for both polymers, as shown in Figure 3 (plot ii). Fibre degradation, due to the longer exposure time, is more pronounced in the epoxy polymer, reaching the lowest strength observed after a drop of $17.55 \%$ (Figure 3, plot ii). Similar behaviour is observed for both solutions considering different treatment times (Figure 3iii). Laminates fabricated with treated fibres using $\mathrm{Na}_{2} \mathrm{CO}_{3}$ for 96 hours presented increase strength. The reference lines for USFPC and USFEC shown in Figures $3 \mathrm{i}$ and 3 iii reveal that the $\mathrm{NaHCO}_{3}$ solution slightly impairs the tensile strength of composites made with the polyester matrix. According to Santos et al. ${ }^{13}$, the fibre-to-fibre stress transfer at fibre intersections is crucial in a random network system of composite fibres. Waxes can enhance fibre slide at fibre intersections. Thus, removing wax layers and other impurities with both sodium carbonate and bicarbonate solutions may improve the axial stress transfer, hence the composite strength. Sodium carbonate establishes a more aggressive alkaline environment $(\mathrm{pH}$ 11.80) than sodium bicarbonate $(\mathrm{pH} 8.30)$ and more deeply remove more external layers of the fibre. This behaviour will be discussed in more detail in Section 3.5.

\subsection{Flexural testing}

Flexural properties also exhibit significant third-order interactions with $\mathrm{P}$-values below 0.05. The third-order interaction plots for flexural strength and stiffness are shown in Figure 4. Based on the reference lines (USFPC and USFEC), all treatment settings are beneficial for bending properties. Higher strength and stiffness values are obtained, for both matrices, when sisal fibres are treated with sodium carbonate. Polyester based composites have $14.04 \%$ and $4.48 \%$ higher flexural stiffness and strength, respectively, than epoxy composites made with $\mathrm{Na}_{2} \mathrm{CO}_{3}$ treated fibres. Lignin exposure can improve the interface region between the polyester resin and the treated fibres since the fibres are more compatible with the polyester resin ${ }^{13}$. Sodium bicarbonate, on the other hand, induces higher flexural modulus (13.38\%) for polyesterand higher strength $(3.69 \%)$ for epoxy-based composites (see Figure $4 \mathrm{a}$ and $4 \mathrm{~b}$, plot $\mathrm{i}$ ). The treatment time also has a remarked influence on the flexural properties, revealing higher values when the composites are manufactured with fibres treated for 96h. Polyester-based composites have a higher flexural modulus than epoxy; however, this effect is not evident for flexural strength (see Figures $4 \mathrm{a}$ and $4 \mathrm{~b}$, plot ii). The effect of treatment time also depends on the type of chemical solution. Higher increments are observed for both strength (14.87\%) and stiffness (18.05\%) for sodium bicarbonate compared to sodium carbonate up to $96 \mathrm{~h}$ (Figure $4 \mathrm{a}, \mathrm{b}$, plot iii). Longer treatments with sodium carbonate, on the other hand, are more harmful to fibres (higher alkalinity), with reductions of up to $12.37 \%$ (stiffness) and $13.53 \%$ (strength) (see Figure $4 \mathrm{a}$ and $4 \mathrm{~b}$, plot iii).

The increase in sisal fibre modulus with sodium bicarbonate $e^{9,12}$ and sodium carbonate reflects on higher flexural modulus of the epoxy and polyester composites ${ }^{13-14}$. The flexural strength is influenced by the fibre-matrix interface ${ }^{9,12-15}$. The enhancement in fibre roughness and the removal of surface waxes and impurities improve fibre-matrix adhesion. The consequent more efficient energy distribution along the surfaces leads to an increase in the load to failure of the composites, and higher flexural strength.

\subsection{Impact testing}

Impact resistance reveals a third-order interaction effect, as shown in Figure 5. Compared to $\mathrm{NaHCO}_{3}$ the treatment with $\mathrm{Na}_{2} \mathrm{CO}_{3}$ shows a slight reduction in impact resistance for polyester composites and a considerable reduction (18.99\%) for epoxy laminates (Figure 5a plot i). It is noteworthy that the $\mathrm{Na}_{2} \mathrm{CO}_{3}$ fibre treatment hinders the impact performance of epoxy composites when compared to the baseline USFEC. The treatment time factor presents similar behaviour for both polymers, reaching higher results for fibres treated for $96 \mathrm{~h}$ (Figure 5a plot ii). While the flexural and tensile properties exhibit better interaction for sodium carbonate and $96 \mathrm{~h}$ treatment time, impact resistance presents better results for sodium bicarbonate. Panels made with fibres treated with sodium bicarbonate have $22.60 \%$ enhanced strength for $96 \mathrm{~h}$ treatment compared to $\mathrm{Na}_{2} \mathrm{CO}_{3}$ (Figure $5 \mathrm{a}$ plot iii). Fibre treatment with $\mathrm{Na}_{2} \mathrm{CO}_{3}$ improves the bonding interface between the reinforcement and matrix, as discussed in Figure 4a (plot iii), affecting the failure mode, especially under dynamic loads ${ }^{25}$. Rather than a pull-out mechanism, sample failure is characterised by fibre rupture ${ }^{13-14}$, which significantly reduces the amount of energy absorbed during impact, especially after fibre treatment with sodium carbonate. Similar behaviour was obtained by Santos et al. ${ }^{13}$ using sodium carbonate treatment and coir fibres reinforced composites.

\subsection{Compressive testing}

A third-order interaction effect is evidenced for the compressive strength, as shown in Table 4. The summary of
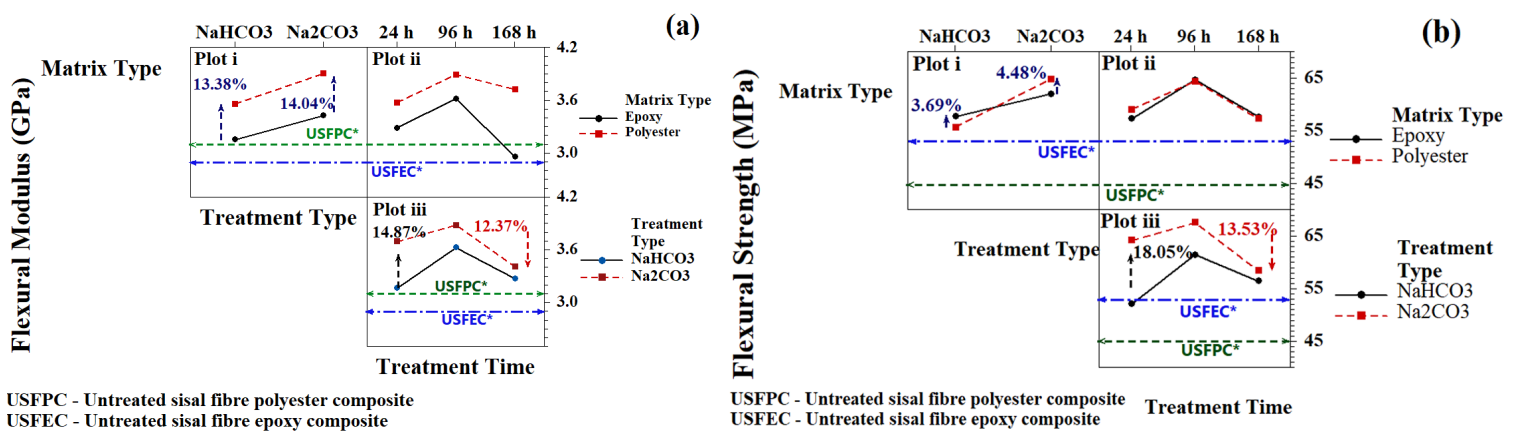

Figure 4. Flexural testing plots for DoE: interaction plots for flexural a) modulus and b) strength. 


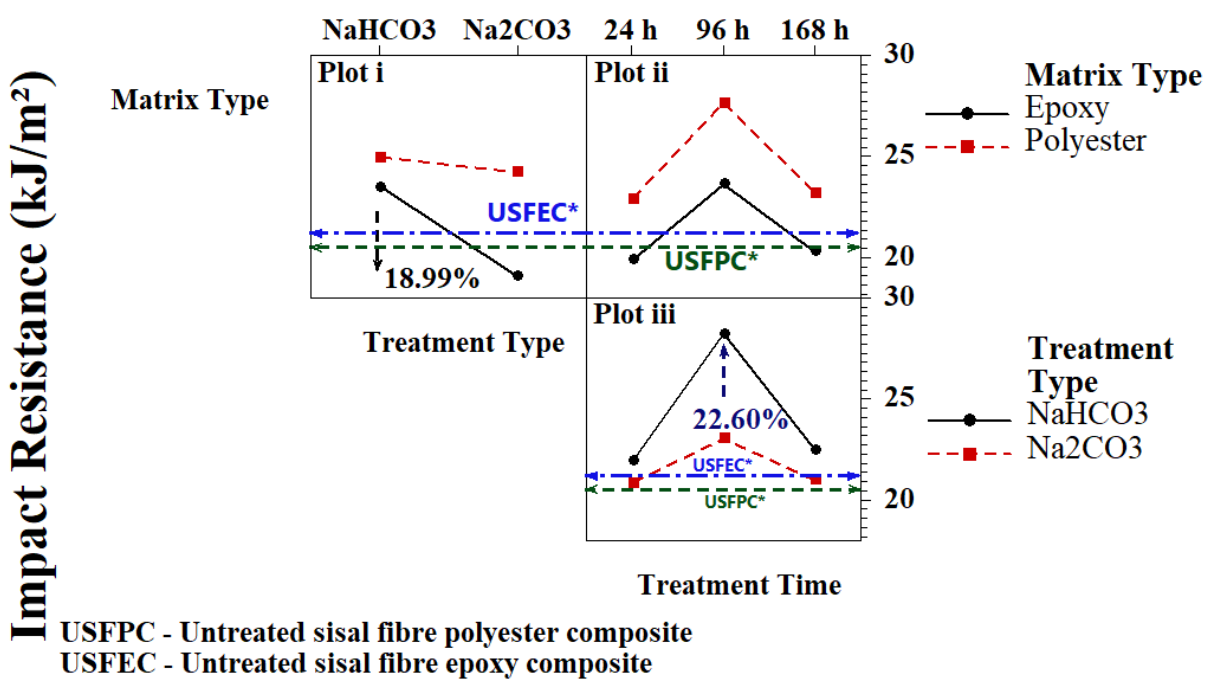

Figure 5. Impact testing (out of plane) interaction plot.

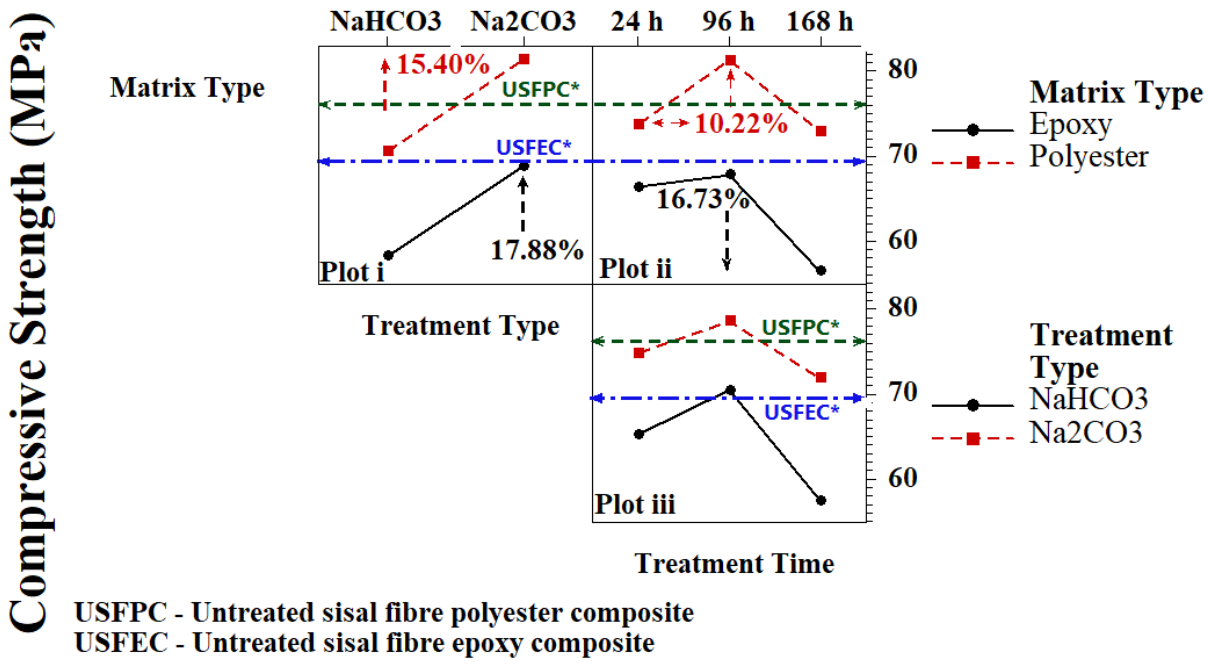

Figure 6. Compressive strength, interaction plots.

interactions is shown in Figure 6. The compressive strength is $15.40 \%$ and $17.88 \%$ higher for composites (both polymers) made from sisal fibres treated with sodium carbonate (see Figure 6 plot i) relative to sodium bicarbonate. However, fibre treatment is only favourable when combining $\mathrm{Na}_{2} \mathrm{CO}_{3}$ and polyester composites, as revealed by the reference conditions (USFPC and USFEC) made with untreated fibres (plot i). The treatment time factor is more favourable at $96 \mathrm{~h}$, mainly for polyester polymer laminates (increment of $10.22 \%$, plot ii). Epoxy-based composites show a significant reduction (up to $16.73 \%$ ) when the fibres are subjected to longer treatments (Figure 6.ii). Both treatments reveal improved strength when the fibres are treated for $96 \mathrm{~h}$ (Figure 6 plot iii). The compressive behaviour is dominated by the mechanical properties of the matrix in fibre-reinforced composites. Polyester composites reveal higher compressive strength since polyester presents superior compressive strength compared to epoxy (Table 3 ).

\subsection{Fracture analysis}

The typical fracture of the composites after tensile, bending, impact and compression tests are shown in Figure 7 from left to right for different conditions: $(a-b)$ untreated sisal fibre composites, (c-d) $\mathrm{NaHCO}_{3}$-treated fibre composites and (e-f) $\mathrm{Na}_{2} \mathrm{CO}_{3}$-treated fibre composites. The fracture modes obtained for all samples are very similar for each test set. Tensile specimens are split into two halves (left), while compressive samples reveal only an apparent crack (right). The bending and impact samples are substantially bent after testing, but, in most cases, fibres hold them as a single piece.

Figure 8 shows the fractures of tensile samples made from $\mathrm{Na}_{2} \mathrm{CO}_{3}$ treated fibres with (a) polyester and (b) epoxy matrices. There is no significant difference between them; 


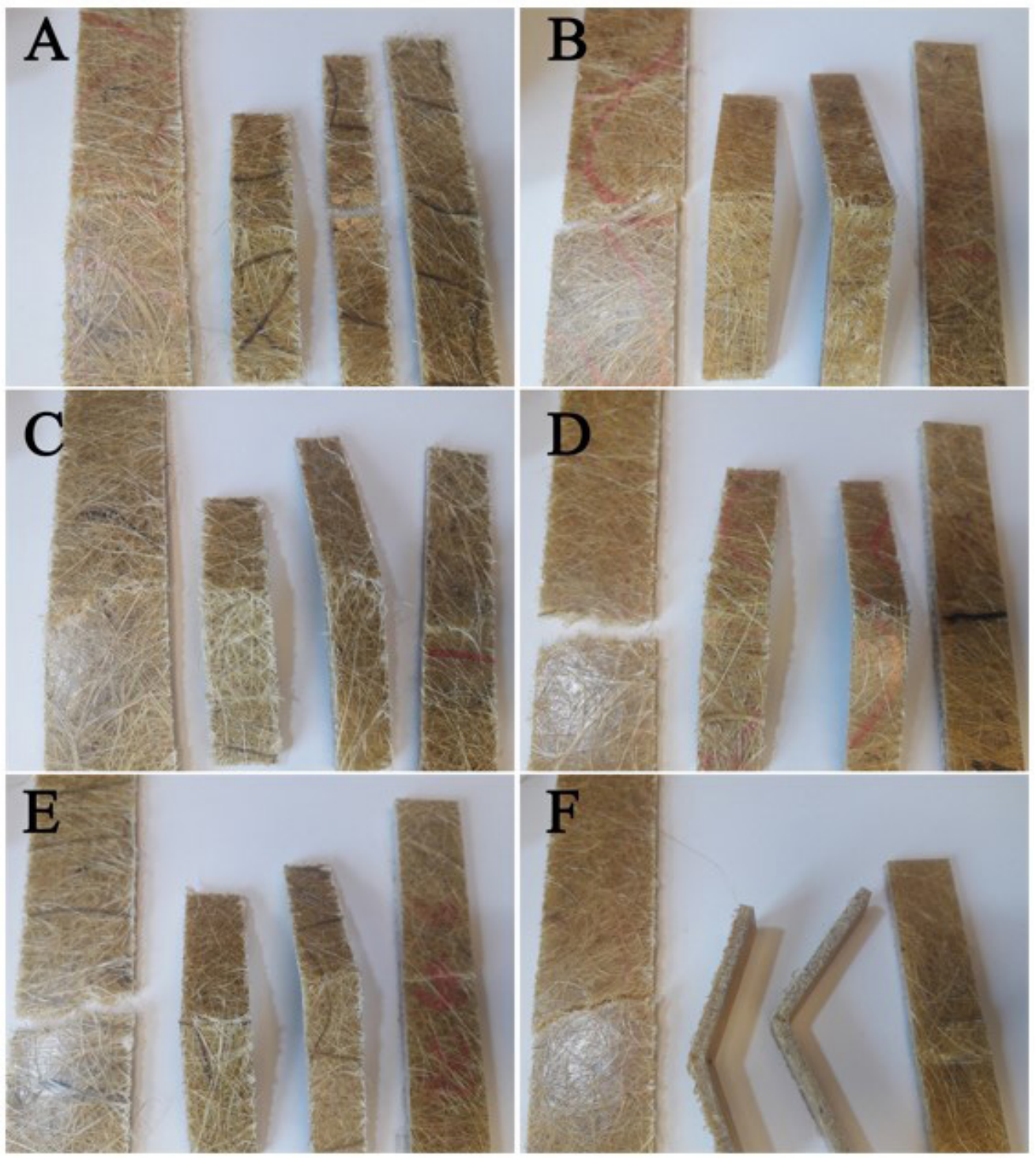

Figure 7. Typical composite fractures composed of (a) untreated fibres and polyester, (b) untreated fibres and epoxy, (c), $\mathrm{NaHCO}_{3}$-treated fibres and polyester, (d) $\mathrm{NaHCO}_{3}$-treated fibres and epoxy, (e) $\mathrm{Na}_{2} \mathrm{CO}_{3}$-treated fibres and polyester and (f) $\mathrm{Na}_{2} \mathrm{CO}_{3}$ treated fibres and epoxy for tensile, bending, impact and compressive samples as shown from left to right.

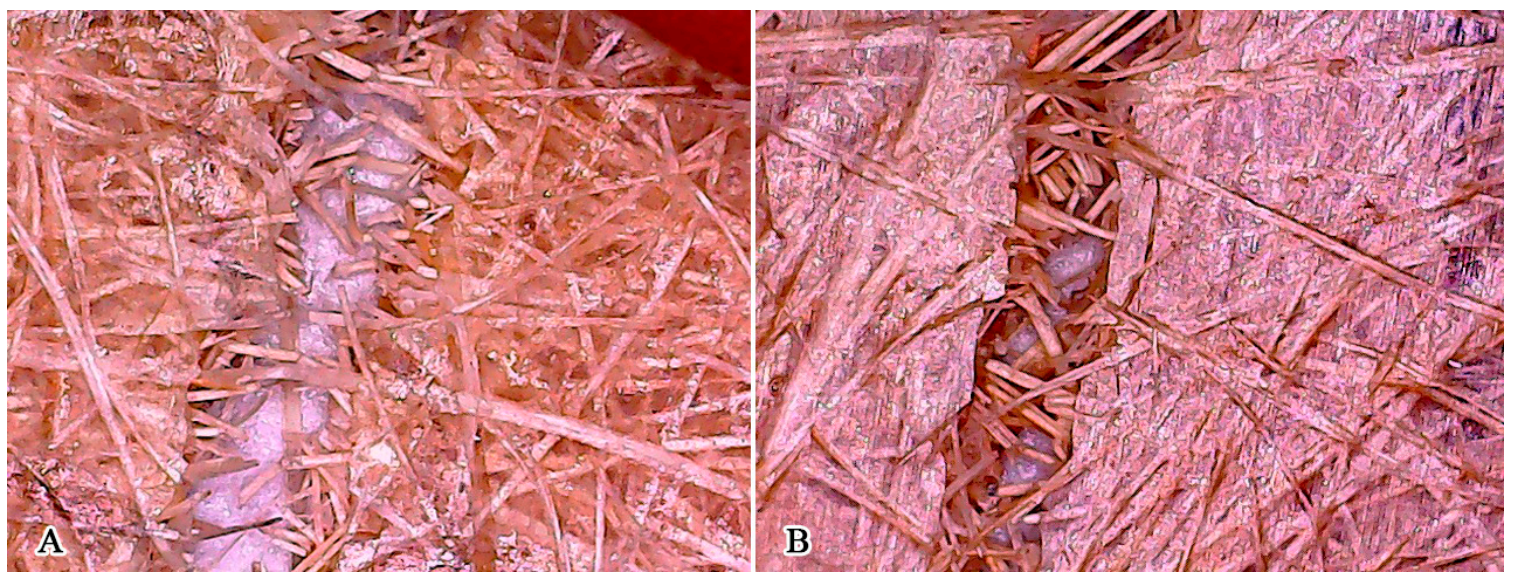

Figure 8. Tensile fractures of (a) polyester and (b) epoxy composites composed of treated fibres with $\mathrm{Na}_{2} \mathrm{CO}_{3}$ for $96 \mathrm{~h}$ 


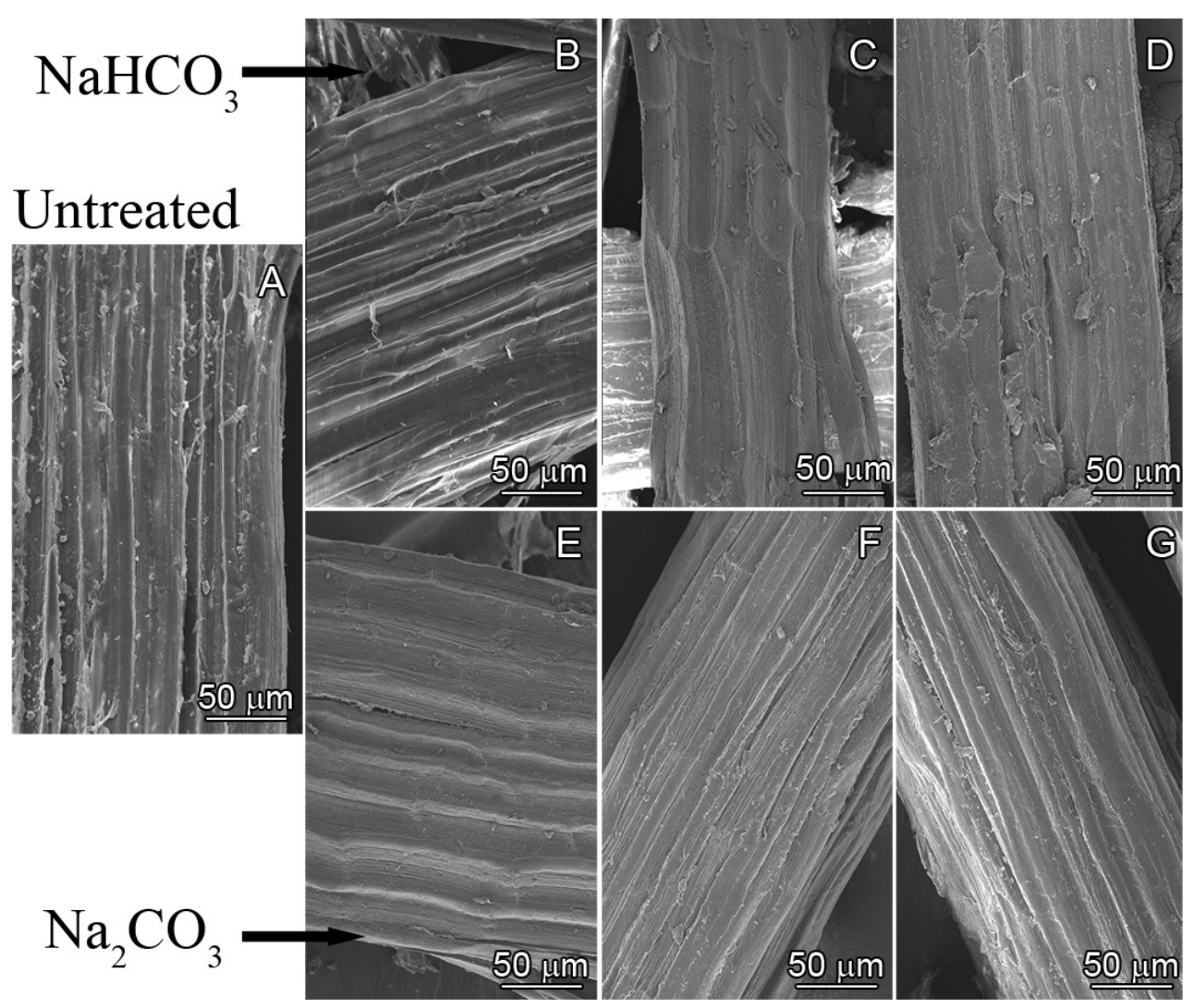

Figure 9. SEM images of sisal fibres: a) untreated; treated with $\mathrm{NaHCO}_{3}$ b) $24 \mathrm{~h}$, c) $96 \mathrm{~h}$ and d) $168 \mathrm{~h}$; treated with $\mathrm{Na}_{2} \mathrm{CO}_{3}$ e) $24 \mathrm{~h}$, f) $96 \mathrm{~h}$ and $\mathrm{g}) 168 \mathrm{~h}$.

fibre pull-out and matrix rupture are mainly evidenced. In general, a greater amount of matrix in the rupture region is obtained by epoxy composites, attributed to their enhanced surface adhesion.

\subsection{SEM, FTIR, X-ray diffraction and thermal analysis}

SEM micrographs of untreated and treated sisal fibres are shown in Figure 9. Untreated fibres exhibit noticeable surface impurities (Figure 9a), e.g., natural waxes and oils, as reported in the literature?. In the manufacturing process of the composite laminates, impurities negatively affect the adhesiveness with the polymer matrix ${ }^{10}$. Figures $9 \mathrm{~b}$ to $9 \mathrm{~g}$ show the surfaces of sisal fibres after different treatment settings. In general, micrographs do not show any detectable impurity on the fibre surface due to the cleaning effect of both solutions. With sodium carbonate treatment at intermediate exposure times, greater surface roughness is obtained, which justifies the greater adhesion and mechanical properties of fibrous composites treated with $\mathrm{Na}_{2} \mathrm{CO}_{3}$.

Comparative FTIR spectra in the range of $400-2.250 \mathrm{~cm}^{-1}$ of untreated and treated $\left(\mathrm{NaHCO}_{3}\right.$ and $\mathrm{Na}_{2} \mathrm{CO}_{3}$ solutions) sisal fibres with varying treatment times $(24,96$ and $168 \mathrm{~h})$ are shown in Figure 10. The letter "a" represents the spectrum of untreated sisal fibres. The characteristic peaks around 1.735 and $1.245 \mathrm{~cm}^{-1}$ indicate the presence of hemicellulose in the fibre composition ${ }^{12,26}$. The intensity of hemicelluloserelated peaks shows marginal reduction for conditions

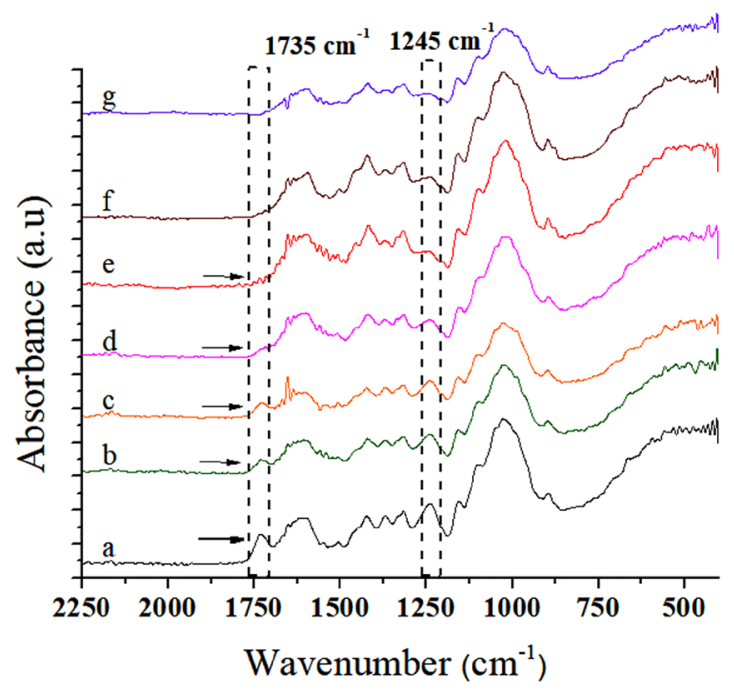

Figure 10. Comparative FT-IR analysis of sisal fibre: a) untreated; treated with $\mathrm{NaHCO}_{3}$ for b) $24 \mathrm{~h} \mathrm{c)} 96 \mathrm{~h}$ and d) $168 \mathrm{~h}$; treated with $\mathrm{Na}_{2} \mathrm{CO}_{3}$ for e) $24 \mathrm{~h} \mathrm{f)} 96 \mathrm{~h}$ and g) $168 \mathrm{~h}$.

treated with $\mathrm{NaHCO}_{3}$ for 24 and $96 \mathrm{~h}$ (Figure $10 \mathrm{~b}$ and c). Peak reduction is more evident after $168 \mathrm{~h}$ of treatment (Figure 6d). Chaitanya et al. ${ }^{12}$ and Santos et al..$^{14}$ also reported similar FTIR findings for $\mathrm{NaHCO}_{3}$-treated sisal and coir fibres, respectively. $\mathrm{Na}_{2} \mathrm{CO}_{3}$ intensifies the peak reduction 

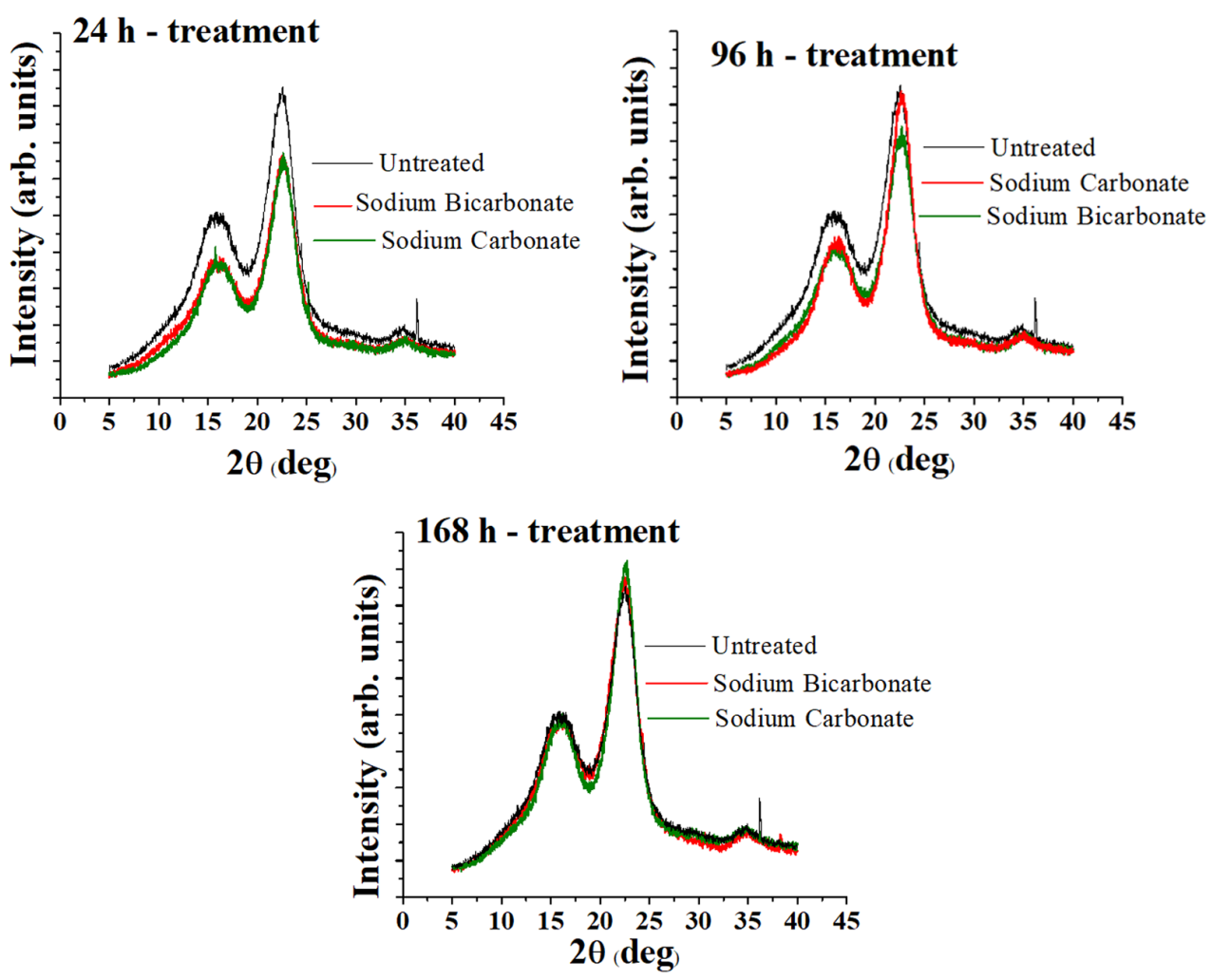

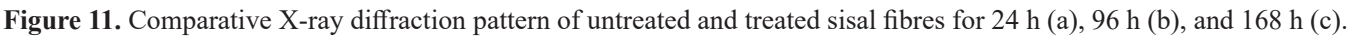

Table 5. X-ray diffraction analysis: crystallinity index $\left(\mathrm{I}_{\mathrm{C}}\right)$.

\begin{tabular}{lccc}
\hline \multirow{2}{*}{ Treatment } & \multicolumn{2}{c}{$2 \theta$} & $\boldsymbol{I}_{\boldsymbol{C}}$ \\
\cline { 2 - 4 } & $\mathbf{2 2}^{\circ} \mathbf{- 2 3}^{\circ}$ & $\mathbf{1 8}^{\circ} \mathbf{- 1 9}{ }^{\circ}$ & $60.75 \%$ \\
\hline Untreated sisal & 4267 & 1675 & $62.61 \%$ \\
\hline Sodium bicarbonate $-24 \mathrm{~h}$ & 3322 & 1242 & $63.53 \%$ \\
\hline Sodium bicarbonate $-96 \mathrm{~h}$ & 3704 & 1351 & $63.31 \%$ \\
\hline Sodium bicarbonate $-168 \mathrm{~h}$ & 4394 & 1612 & $64.35 \%$ \\
\hline Sodium carbonate $-24 \mathrm{~h}$ & 3355 & 1196 & $68.98 \%$ \\
\hline Sodium carbonate $-96 \mathrm{~h}$ & 4619 & 1433 & $70.18 \%$ \\
\hline Sodium carbonate $-168 \mathrm{~h}$ & 4185 & 1248 & \\
\hline
\end{tabular}

(Figure 10e to g) compared to $\mathrm{NaHCO}_{3}$ for all treatment times, indicating a partial removal of hemicellulose and waxes from the fibre surface. A greater amount of $\mathrm{OH}^{-}$ions, released by the $\mathrm{Na}_{2} \mathrm{CO}_{3}$ solution (see Table 2), leads to greater removal of the wax layer and hemicellulose, affecting the surface wettability and mechanical properties of the resulting composite laminates ${ }^{13}$.

The X-ray diffraction analyses are shown in Table 5. Figure 11 presents the diffraction patterns of untreated and treated sisal fibres after $24 \mathrm{~h}, 96 \mathrm{~h}$ and $168 \mathrm{~h}$ (Figure $11 \mathrm{a}$ to c). The intensity of the amorphous phase identified by $2 \theta$ between $18^{\circ}$ and $19^{\circ}$ is significantly reduced with fibre treatment, especially for shorter treatment times of up to $96 \mathrm{~h}$ (see Table 5 and Figure 11). It evidences an effective caustic action on the fibre surface, removing impurities, waxes and segments of amorphous components, i.e. hemicellulose and some amount of lignin. A higher crystallinity index is observed for fibres treated with sodium carbonate during
$168 \mathrm{~h}$ (Table 5), contrasting with the moderate increase obtained with sisal treated with sodium bicarbonate.

The thermogravimetric (TGA) and differential thermogravimetric (DTG) curves are shown in Figure 12, items a and b, respectively. Sisal fibres have three stages of thermal degradation. The drops described by the TGA curves as a function of temperature represent the weight loss (\%) of treated and untreated sisal filament samples. The first stage takes place at 30 to $120^{\circ} \mathrm{C}^{12,14}$, corresponding to water removal from environmental humidity. Fibres treated with $\mathrm{Na}_{2} \mathrm{CO}_{3}$ show a similar trend compared to sisal fibres treated with $\mathrm{NaHCO}_{3}$. The susceptibility of the fibres to moisture is gradually reduced with increasing treatment time. A similar observation was reported by Chaitanya et al. ${ }^{12}$, analysing sisal fibres treated with $\mathrm{NaHCO}_{3}$. Therefore, this implies that long exposure times in carbonate solutions (168 h) can change the hydrophilicity of sisal fibre surfaces. The thermal degradation of sisal fibres begins after $230^{\circ} \mathrm{C}$ and corresponds to the removal of hemicellulose $\left(230\right.$ to $\left.295^{\circ} \mathrm{C}\right)$, cellulose $\left(300\right.$ to $\left.400^{\circ} \mathrm{C}\right)$ and 
(a)

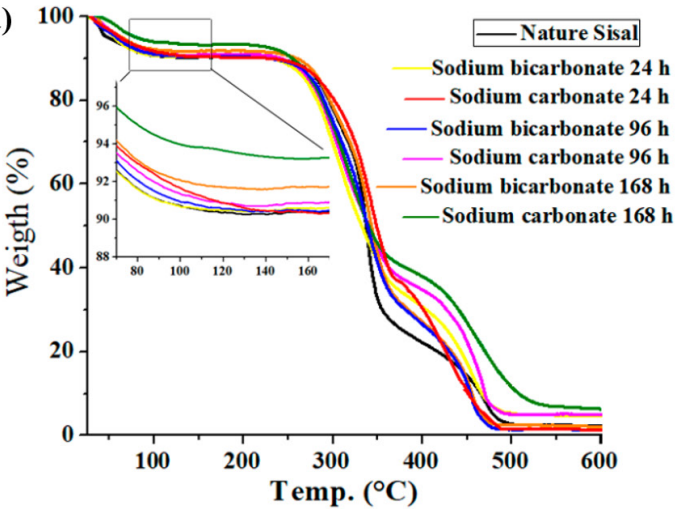

(b)

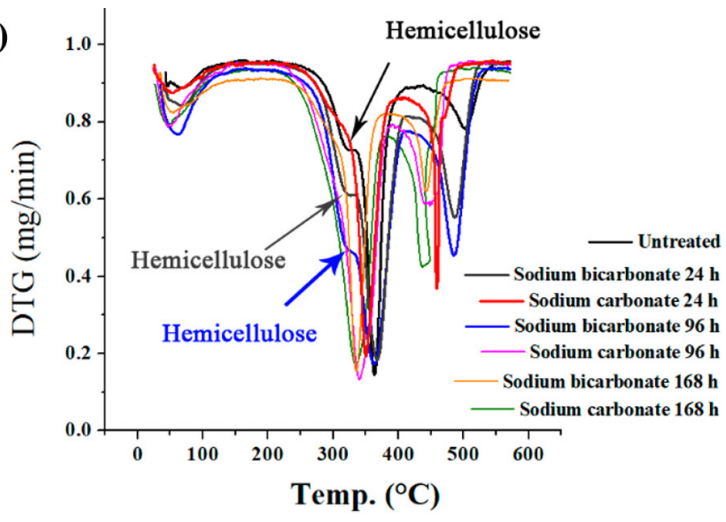

Figure 12. (a) TGA and (b) DTG thermographs of sisal fibres untreated and treated with $\mathrm{Na}_{2} \mathrm{CO}_{3}$ and $\mathrm{NaHCO}_{3}(24,96$ and 18 hours).

lignin compounds on the fibre surface (above $\left.400^{\circ} \mathrm{C}\right)^{9,12,27}$. A hemicellulose shoulder peak can be seen in the DTG curves of untreated and $\mathrm{NaHCO}_{3}$ treated fibres (24 and $96 \mathrm{~h}$ ). The absence of this broad peak for the other fibres corresponds to the pyrolysis of hemicellulose, which is more pronounced for the treatment with $168 \mathrm{~h}-\mathrm{NaHCO}_{3}$ and $\mathrm{Na}_{2} \mathrm{CO}_{3}$ at all-time levels.

\section{Conclusions}

This work investigates the effect of carbonate treatments of sisal fibres on the properties of laminate composites based on epoxy and polyester polymers. The main conclusions are described below:

i. The tensile modulus is higher for laminates made with polyester polymer and sisal fibres treated with $\mathrm{Na}_{2} \mathrm{CO}_{3}$ for $96 \mathrm{~h}$. Tensile strength is superior when fibres are treated with $\mathrm{Na}_{2} \mathrm{CO}_{3}$, especially for epoxy.

ii. The flexural modulus is higher for polyester polymer composites reinforced with treated sisal fibres, especially using $\mathrm{Na}_{2} \mathrm{CO}_{3}$ in the intermediate treatment time $(96 \mathrm{~h})$. In contrast, an interaction effect between the type of treatment and matrix is evidenced for the flexural strength response, revealing less variation. Longer treatments lead to a severe reduction in strength and stiffness.

iii. Impact resistance is reduced when sisal fibres are treated with $\mathrm{Na}_{2} \mathrm{CO}_{3}$, mainly for epoxy polymer composites, attributed to the stronger fibre-matrix interface. Fibres treated with $\mathrm{NaHCO}_{3}$ for $96 \mathrm{~h}$ reveal enhanced impact results due to the fibre pull-out mechanism, especially when the polyester polymer is used.

iv. Fibre treatment is only favourable for compressive strength when combining $\mathrm{Na}_{2} \mathrm{CO}_{3}$ and polyester composites. Compressive properties are substantially increased with $\mathrm{Na}_{2} \mathrm{CO}_{3}$ treatment, especially for $96 \mathrm{~h}$.

v. SEM analyses reveal a smooth fibre surface with no visible contaminants for both tested solutions. In addition, FTIR spectroscopy indicates progressive removal of hemicellulose from the fibres with $\mathrm{NaHCO}_{3}$ with longer treatments and no visible peaks for the hemicellulose when fibres are treated with $\mathrm{Na}_{2} \mathrm{CO}_{3}$. Similar conclusions are also obtained from XRD patterns and thermogravimetric analysis of sisal fibres.
These results evidence the applicability of the proposed composite in the field of sustainable structures, ensuring enhanced mechanical performance with a chemical treatment less harmful to nature.

\section{Acknowledgments}

The authors would like to thank CAPES (post-doctoral fellowship 88882.314574/2019-01), CNPq (PQ 309885/2019-1) and FAPEMIG (PPM) for the financial support provided.

\section{References}

1. Ramesh M, Palanikumar K, Reddy KH. Plant fibre based bio-composites: sustainable and renewable green materials. Renew Sustain Energy Rev. 2017;79:558-84. http://dx.doi. org/10.1016/j.rser.2017.05.094.

2. Thakur VK, Thakur MK. Processing and scharacterisation of natural cellulose fibers/thermoset polymer composites. Carbohydr Polym. 2014;109:102-17. http://dx.doi.org/10.1016/j. carbpol.2014.03.039.

3. Haghdan S, Smith GD. Natural fiber reinforced polyester composites: a literature review. J Reinf Plast Compos. 2015;34:1179-90. http://dx.doi.org/10.1177/0731684415588938.

4. Kumar SMS, Duraibabu D, Subramanian K. Studies on mechanical, thermal and dynamic mechanical properties of untreated (raw) and treated coconut sheath fiber reinforced epoxy composites. Mater Des. 2014;59:63-9. http://dx.doi. org/10.1016/j.matdes.2014.02.013.

5. Pickering KL, Efendy MGA, Le TM. A review of recent developments in natural fibre composites and their mechanical performance. Compos. Appl. Sci. Manuf. 2016;83:98-112. http://dx.doi.org/10.1016/j.compositesa.2015.08.038.

6. Reis JML. Sisal fiber polymer mortar composites: introductory fracture mechanics approach. Constr Build Mater. 2012;37:17780. http://dx.doi.org/10.1016/j.conbuildmat.2012.07.088.

7. Mukherjee PS, Satyanarayana KG. Structure and properties of some vegetable fibres. J Mater Sci. 1984;19:3925-34. http:/ dx.doi.org/10.1007/bf00980755.

8. Jiang A, Xu X, Wu H. Preparation and properties ofL-lactidegrafted sisal fiber-reinforced poly(lactic acid) composites. Polym Compos. 2014;37:802-9. http://dx.doi.org/10.1002/pc.23237.

9. Fiore V, Scalici T, Nicoletti F, Vitale G, Prestipino M, Valenza A. A new co-friendly chemical treatment of natural fibres: effect of sodium bicarbonate on properties of sisal fibre and its epoxy composites. Compos, Part B Eng. 2016;85:150-60. http://dx.doi.org/10.1016/j.compositesb.2015.09.028. 
10. Fiore V, Di Bella G, Valenza A. The effect of alkaline treatment on mechanical properties of kenaf fibers and their epoxy composites. Compos, Part B Eng. 2015;68:14-21. http://dx.doi. org/10.1016/j.compositesb.2014.08.025.

11. Fiore V, Scalici T, Valenza A. Effect of sodium bicarbonate treatment on mechanical properties of flax-reinforced epoxy composite materials. J Compos Mater. 2017;52(8):1061-72. http://dx.doi.org/10.1177/0021998317720009.

12. Chaitanya S, Singh I. Sisal fiber-reinforced green composites: effect of ecofriendly fiber treatment. Polym Compos. 2018;39(12):4310-21. http://dx.doi.org/10.1002/pc.24511.

13. Santos JC, Siqueira RL, Vieira LMG, Freire RTS, Mano V, Panzera TH. Effects of sodium carbonate on the performance of epoxy and polyester coir-reinforced composites. Polym Test. 2018;67:53344. http://dx.doi.org/10.1016/j.polymertesting.2018.03.043.

14. Santos JC, Oliveira LÁ, Vieira LMG, Mano V, Freire RTS, Panzera TH. Eco-friendly sodium bicarbonate treatment and its effect on epoxy and polyester coir fibre composites. Constr Build Mater. 2019;211:427-36. http://dx.doi.org/10.1016/J. CONBUILDMAT.2019.03.284.

15. Mirmohamadsadeghi S, Chen Z, Wan C. Reducing biomass recalcitrance via mild sodium carbonate pretreatment. Bioresour Technol. 2016;209:386-90. http://dx.doi.org/10.1016/j. biortech.2016.02.096.

16. Montgomery DC. Introduction to statistical quality control. USA: Wiley; 1997.

17. Olveira LÁ, Santos JC, Panzera TH, Freire RTS, Vieira LMG, Rubio JCC. Investigations on short coir fibre-reinforced composites via full factorial design. Polym Polymer Compos. 2018;26(7):391-9. http://dx.doi.org/10.1177/0967391118806144.

18. Oliveira L, Santos JC, Panzera TH, Freire RTS, Vieira LMG, Scarpa F. Evaluation of hybrid-short-coir-fibre-reinforced composites via full factorial design. Compos Struct. 2018;202:313-23. http://dx.doi.org/10.1016/j.compstruct.2018.01.088.
19. ASTM: American Society for Testing and Materials. ASTM D3039/D3039M-17: standard test method for tensile properties of polymer matrix composite materials. West Conshohocken: ASTM; 2017.

20. ASTM: American Society for Testing and Materials. ASTM D790-17: standard test methods for flexural properties of unreinforced and reinforced plastics and electrical insulating materials. West Conshohocken: ASTM; 2017.

21. ASTM: American Society for Testing and Materials. ASTM D8066/ D8066M-17: standard practice unnotched compression testing of polymer matrix composite laminates. West Conshohocken: ASTM; 2017.

22. ISO - International Organization for Standardization. ISO 179: Plastics - determination of charpy impact properties. Part 1. Geneva: ISO; 2010.

23. Xu J, Jiang J, Dai W, Xu Y. Liquefaction of sawdust in hot compressed ethanol for the production of bio-oils. Process Saf Environ Prot. 2012;90:333-8. http://dx.doi.org/10.1016/j. psep.2012.01.001

24. Prasad SV, Pavithran C, Rohatgi PK. Alkali treatment of coir fibres for coirpolyester composites. J Mater Sci. 1983;18:144354. http://dx.doi.org/10.1007/BF01111964.

25. Wang C, Ji X, Roy A, Silberschmidt VV, Chen Z. Shear strength and fracture toughness of carbon fibre/epoxy interface: effect of surface treatment. Mater Des. 2015;85:800-7. http://dx.doi. org/10.1016/j.matdes.2015.07.104.

26. Ye C, Ma G, Fu W, Wu H. Effect of fiber treatment on thermal properties and crystallization of sisal fiber reinforced polylactide composites. J Reinf Plast Compos. 2015;34(9): 718-30. https:// doi.org/10.1177/0731684415579090

27. Vieira LMG, Santos JC, Panzera TH, Christoforo AL, Mano V, Rubio JCC, et al. Hybrid composites based on sisal fibers and silica nanoparticles. Polym Compos. 2016;39(1):146-56. https://doi.org/10.1002/pc.23915. 